\title{
Phenothiazine-Based Polymer Cathode Materials with Ultrahigh Power Densities for Lithium Ion Batteries
}

\author{
Brian M. Peterson, ${ }^{\S} \dagger$ Dong Ren, ${ }^{\S, \dagger}$ Luxi Shen, ${ }^{\S} \dagger$ You-Chi Mason Wu, ${ }^{\S}$ Burak Ulgut, ${ }^{\ddagger}$ \\ Geoffrey W. Coates, ${ }^{\S \odot}$ Héctor D. Abruña, ${ }^{\S}{ }^{\circledR}$ and Brett P. Fors ${ }^{*},{ }^{\circledR}$ \\ ${ }^{\S}$ Department of Chemistry and Chemical Biology, Baker Laboratory, Cornell University, Ithaca, New York 14853-1301, United \\ States \\ ${ }^{\ddagger}$ Department of Chemistry, Bilkent University, Ankara 06800, Turkey
}

\section{Supporting Information}

ABSTRACT: Lithium ion batteries (LIBs) currently deliver the highest energy density of any known secondary electrochemical energy storage system. However, new cathode materials, which can deliver both high energy and power densities, are needed to improve LIBs. Herein, we report on the synthesis of a new organic-based redox-active material centered about phenothiazine and phenylenediamine units. Improved Coulombic efficiencies and greater capacity retention during cycling are observed through the copolymerization of a phenothiazine-based monomer that yields cross-linked materials. With this as the positive electrode in Li-coin cells, high specific capacities $(150 \mathrm{mAh} / \mathrm{g})$ are delivered at very positive operating voltages $(2.8-4.3 \mathrm{~V}$ vs $\mathrm{Li}^{+} / \mathrm{Li}$ ), yielding high energy densities. The material has low charge transfer resistance as verified by electrochemical impedance spectroscopy, which contributes in delivering previously unseen power densities in coin cells for organic-based cathodes. Excellent retention of capacity $(82 \%)$ is observed at ultrafast discharge rates $(120 \mathrm{C})$.

KEYWORDS: lithium ion batteries, organic cathode materials, polymer cathode materials, secondary batteries, phenothiazine

$\mathrm{O}$ rganic and polymeric materials are excellent candidates for next generation electrode materials in high-power and high-energy density electrochemical energy storage applications, namely, lithium ion batteries (LIBs). ${ }^{1-3}$ Relative to traditional metal oxide cathodes, organic materials are structurally tunable, environmentally benign, and elementally abundant, lending to their continued study as potential cathodes. Polymers centered about conductive, ${ }^{4,5}$ carbonylbased, $^{6-9}$ nitroxide radical, ${ }^{10,11}$ and organosulfur ${ }^{12-14}$ functionalities have shown exceptional performance and promise as cathodes in LIBs (see Supporting Information Figure S1). However, designing organic cathodes which exhibit both high power density, characteristic of capacitors, and high energy density, often associated with batteries, remains intrinsically challenging.

In the quest for high energy density organic cathodes, p-type polymers are particularly enticing, owing in part to their high operating voltages. ${ }^{15-18}$ Recently reported phenothiazinebased p-type polymer cathodes exhibit stable cycling and high working voltages. ${ }^{19-21}$ However, low capacities are delivered due to only a single electron being exchanged (via oxidation) per repeat unit. Encouraged by these reports, we sought to design a class of phenothiazine main-chain polymers which would undergo multiple electron oxidations and deliver high capacities (Figure 1). Incorporation of redox functionality directly into the main chain minimizes supporting mass per redox event, affording high theoretical gravimetric capacities. Furthermore, a partially conjugated structure should provide a framework for low resistance toward electronic conduction throughout the cathode. Adhering to these design principles, we present a redox-active phenothiazine centered polymer cathode, which effectively couples high energy density and power density.

Through rational design, we sought to synthesize phenothiazine-based polymer cathodes capable of delivering high power densities at fast charging and discharging rates. We hypothesized that copolymerization of $N$-methylphenothiazine (1) with electron rich and redox-active aryl diamines would afford polymers with high theoretical capacities and stable charged states by mimicking the stabilized oxidized state of methylene blue. Two aryl amines, $N, N, N^{\prime}, N^{\prime}$-tetramethyl- $p$ phenylenediamine (2) and $N, N, N^{\prime}, N^{\prime}$-tetramethylbenzidine (3), were natural candidates considering their multiple oxidation events to a stabilized quinoidal dication at potentials greater than $3.3 \mathrm{~V}$ vs $\mathrm{Li}^{+/} \mathrm{Li}^{22}$ We further hypothesized that

Received: May 16, 2018

Accepted: August 3, 2018

Published: August 3, 2018 
(a)

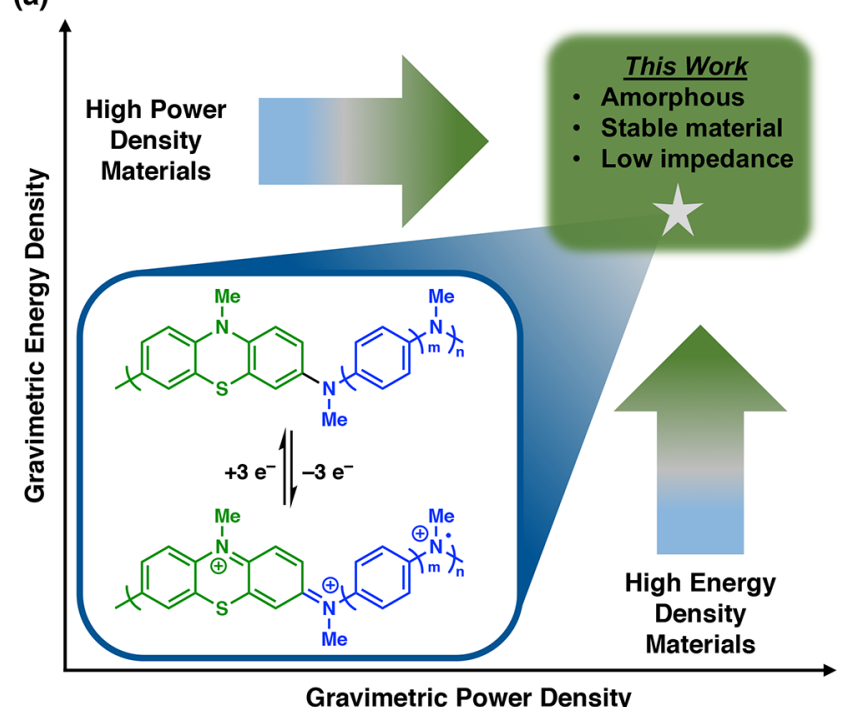

(b) Small Molecule Inspiration

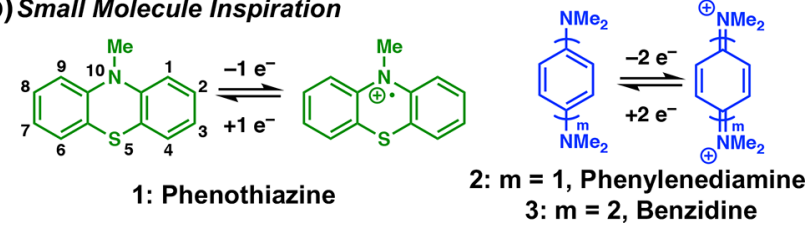

Figure 1. (a) Charged and discharged states of high energy density and high power density poly $(N$-methylphenothiazine dimethylphenylenediamine) (PT-DMPD, $m=1)$ and poly $(N$-methylphenothiazine benzidine) (PT-BZ, $m=2$ ). (b) The oxidized and reduced states of the small molecule basis.

copolymerization through the 3 and 7 positions of phenothiazine would facilitate fast charging and discharging rates, since partial conjugation throughout the entire backbone would allow for facile electron transfer to and from the current collector.

Poly (N-methylphenothiazine dimethylphenylenediamine) (PT-DMPD) and poly $(N$-methylphenothiazine benzidine) (PT-BZ) were synthesized from inexpensive starting materials using a Buchwald-Hartwig cross-coupling of 3,7-dibromo- $\mathrm{N}$ methylphenothiazine (1a) with dimethylphenylenediamine (2a) or dimethylbenzidine (3a) (Figure 2a). ${ }^{23,24}$ The resulting linear polymers were insoluble in their neutral state, and their electrochemical properties were probed using cyclic voltammetry $(\mathrm{CV})$, measured as slurries deposited on a glassy carbon electrode in contact with a solution of $\operatorname{LiPF}_{6}(1 \mathrm{M})$ in ethylene carbonate/diethyl carbonate (EC/DEC). The neutral and oxidized redox states of PT-DMPD are displayed in Figure 1. The three discrete redox couples of each polymer were observed by CV (Figure 2b), occurring at 3.3, 3.6, and $4.3 \mathrm{~V}$ vs $\mathrm{Li} / \mathrm{Li}^{+}{ }^{25}$ These redox couples are among the highest for organic electrodes reported for electrical energy storage applications.

Coin cells employing PT-DMPD or PT-BZ as the cathode and $\mathrm{Li}$ metal as the anode were assembled to explore the performance of the polymers in devices. Due to the limited stability window of the electrolyte medium (EC/DEC), only the first two redox couples were accessed in coin cell cycling (see Figure S2). Coin cells were prepared on carbon felt current collectors with $0.55 \mathrm{mg} / \mathrm{cm}^{2}$ active material loading (see Supporting Information for coin cell fabrication). Figure 3a displays the first cycle charge-discharge profiles of PT-

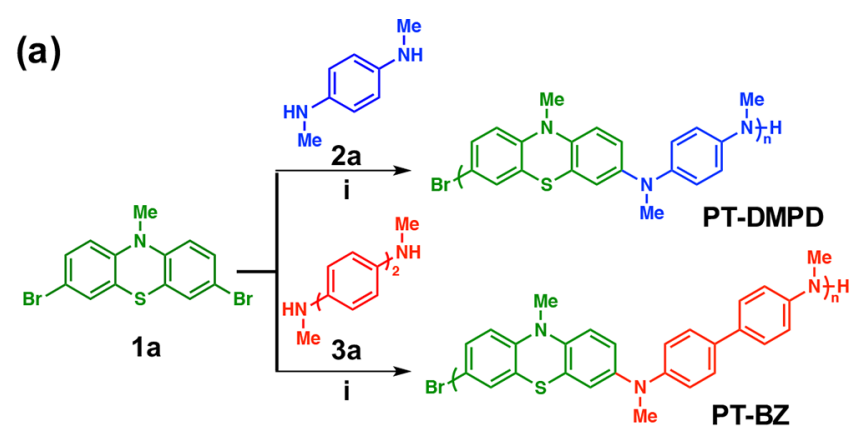

(b)

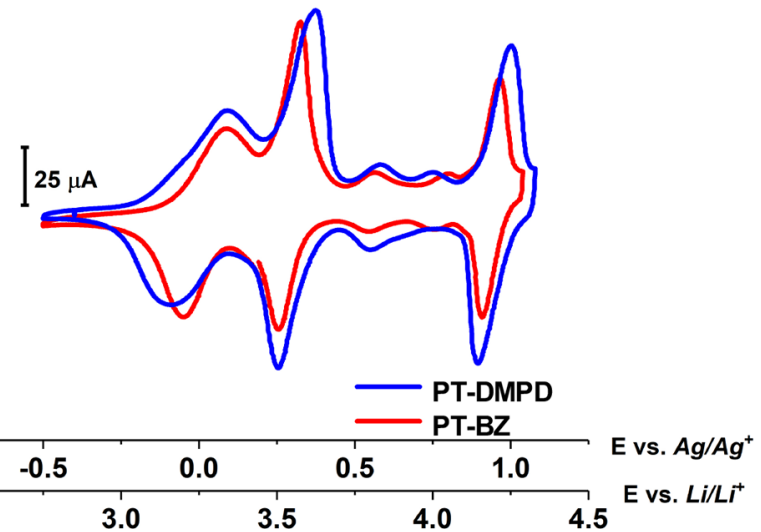

Figure 2. (a) General synthetic strategy toward PT-DMPD and PT$\mathrm{BZ}$ polymers using Buchwald-Hartwig coupling: (i) $\mathrm{NaO} t \mathrm{Bu}$, RuPhos (3 mol \%), RuPhos Pd G2 (3 mol \%), toluene, $80{ }^{\circ} \mathrm{C}$; (b) slurry CV of PT-DMPD and PT-BZ in $\mathrm{LiPF}_{6}(1 \mathrm{M})$ in EC/DEC at 20 $\mathrm{mV} \mathrm{s}^{-1}$.

DMPD and PT-BZ at $1 \mathrm{C}$, over the voltage range from 2.8 to 4.3 V. Both exhibit reversible two-stage charge-discharge behavior, which is consistent with the two major redox couples observed in the CV. The discharge capacities of PT-DMPD and PT-BZ were $128 \mathrm{mAh} / \mathrm{g}$ and $97 \mathrm{mAh} / \mathrm{g}$, representing 82\% and $76 \%$ of theoretical capacity, respectively. However, both materials exhibited a relatively low Coulombic efficiency $(35 \%$ for PT-DMPD and 44\% for PT-BZ). The cycling performances of the PT-DMPD and PT-BZ cathode materials are shown in Figure $3 \mathrm{~b}$. Both cells were cycled at $25{ }^{\circ} \mathrm{C}$ over the same voltage range at $1 \mathrm{C}$. The discharge capacity of PT-DMPD was $82 \mathrm{mAh} / \mathrm{g}$ after 50 cycles (64\% retention), while that of PT-BZ was $64 \mathrm{mAh} / \mathrm{g}$ after 50 cycles (66\% retention). Since the PTDMPD polymer exhibited higher capacity than PT-BZ polymer, further work focused on the former.

We hypothesized that the low Coulombic efficiency and capacity fade upon cycling were caused by dissolution of the polymer upon oxidation. This dissolution could be observed visually as green dissolved polymer diffused away from the electrode during CV cycling. To address these limitations, a second class of increasingly cross-linked materials was synthesized to generate polymers with decreased solubility in the electrolyte medium (Figure 4a). This class of cross-linked cathode materials is referenced according to the mol percentage of cross-linker relative to 1a. The first chargedischarge cycles of PT-DMPD, PT-DMPD (5\% cross-linked, $5 \% \mathrm{CL})$, PT-DMPD (10\% CL), and PT-DMPD (33\% CL) at $5 \mathrm{C}$ are shown in Figure $4 \mathrm{~b}$. Increased discharge capacities trended with an increase in mol percentage of cross-linker, with PT-DMPD (10\% CL) exhibiting the highest discharge capacity of $150 \mathrm{mAh} / \mathrm{g}$ (97\% of the theoretical value of PT-DMPD). In 

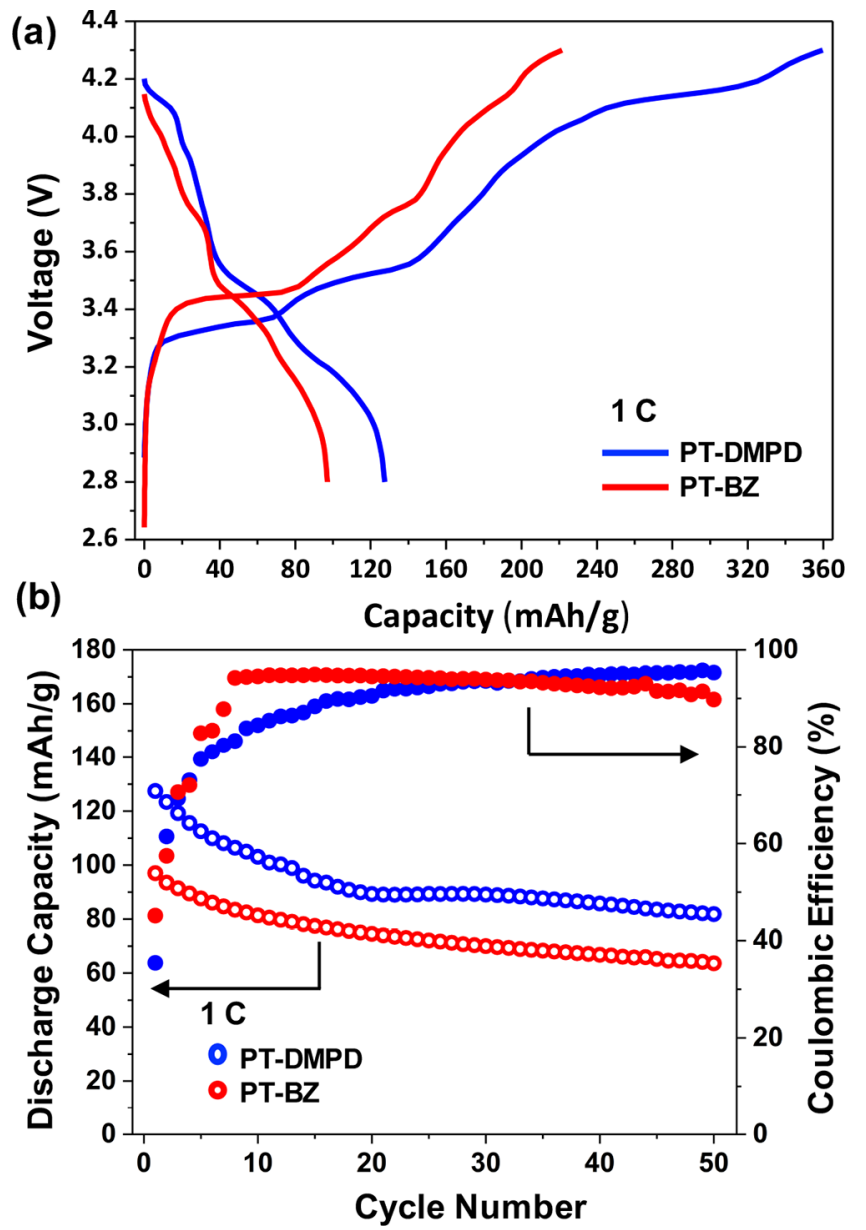

Figure 3. (a) Initial charge-discharge profiles of coin cells, prepared with $0.55 \mathrm{mg} / \mathrm{cm}^{2}$ loading of PT-DMPD and PT-BZ, at 1 C. (b) Cycling performance of the PT-DMPD and PT-BZ cells at $1 \mathrm{C}$.

addition, a decrease in charging capacity led to significant improvements in Coulombic efficiency with increasing copolymerization of cross-linker. It is likely that the decrease in charging capacity results from either a suppression of polymer degradation or a decrease in small, soluble oligomers, which can act as electron shuttles between electrodes during charging. ${ }^{26-28}$ The Coulombic efficiency at $5 \mathrm{C}$ increases from $49 \%$ to $82 \%$ between linear (no cross-linker) and 33\% crosslinked polymer. By limiting dissolution through cross-linking, both the capacity and Coulombic efficiency were dramatically improved.

The cycling performance of PT-DMPD, PT-DMPD (5\% CL), PT-DMPD ( $10 \% \mathrm{CL}$ ), and PT-DMPD (33\% CL) materials was investigated between 2.8 and $4.3 \mathrm{~V}$ at $5 \mathrm{C}$, as shown in Figure 4c. Increasing the mol percentage of crosslinker resulted in materials exhibiting better cycling performance when compared to that of linear PT-DMPD. As the mol percentage of cross-linker increased from $0 \%$ to $5 \%$ to $10 \%$ to $33 \%$, the capacity retention after 50 cycles increased from $65 \%$ to $73 \%$ to $74 \%$ to $82 \%$, respectively. These results suggest that dissolution of the polymer from the cathode was largely mitigated in the cross-linked materials.

For use in high power applications, the proposed materials must be able to deliver high discharge capacities at fast discharge rates. To better understand the relationship between mol \% cross-linker and the materials capacity retention at

(a)
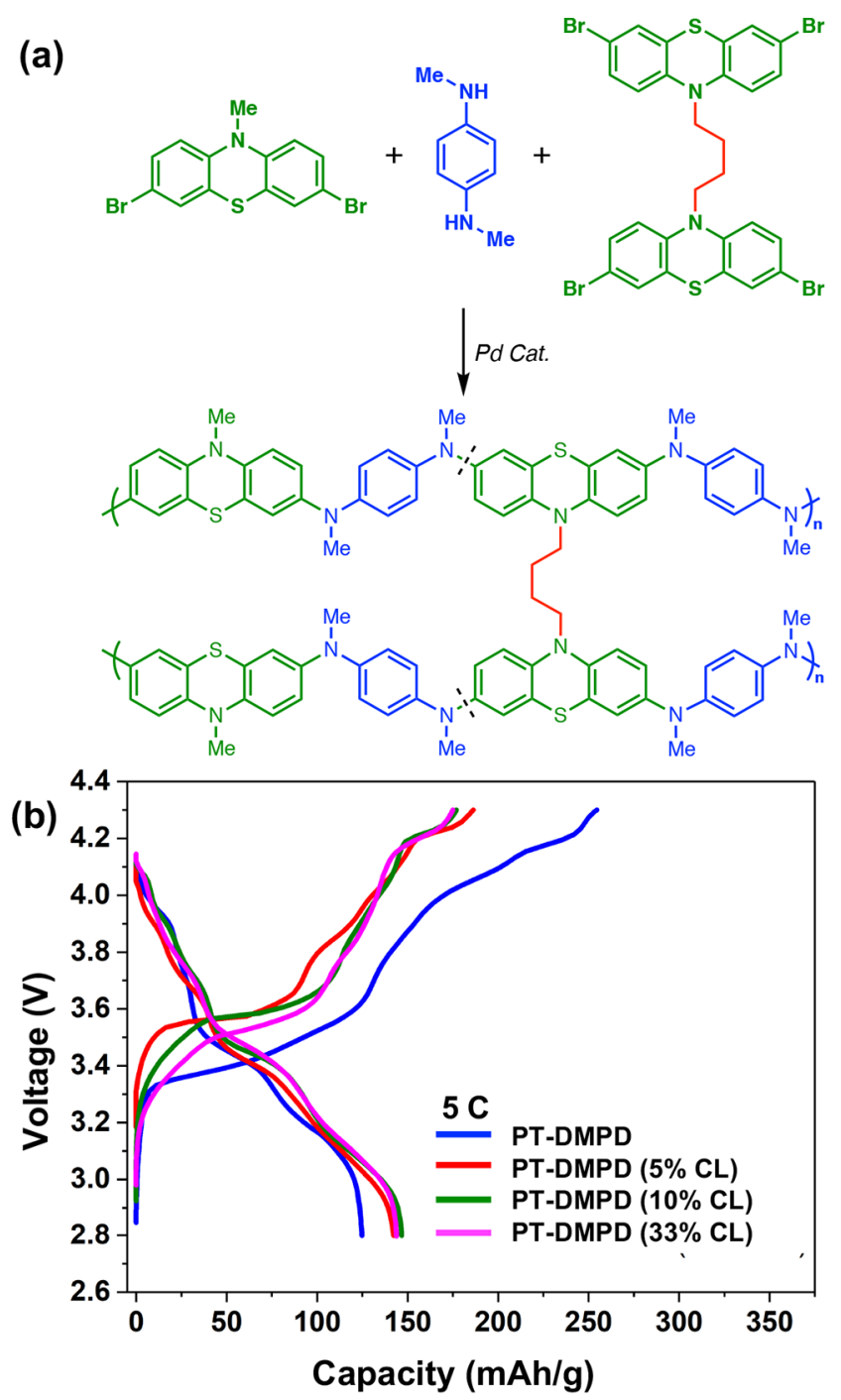

(c)

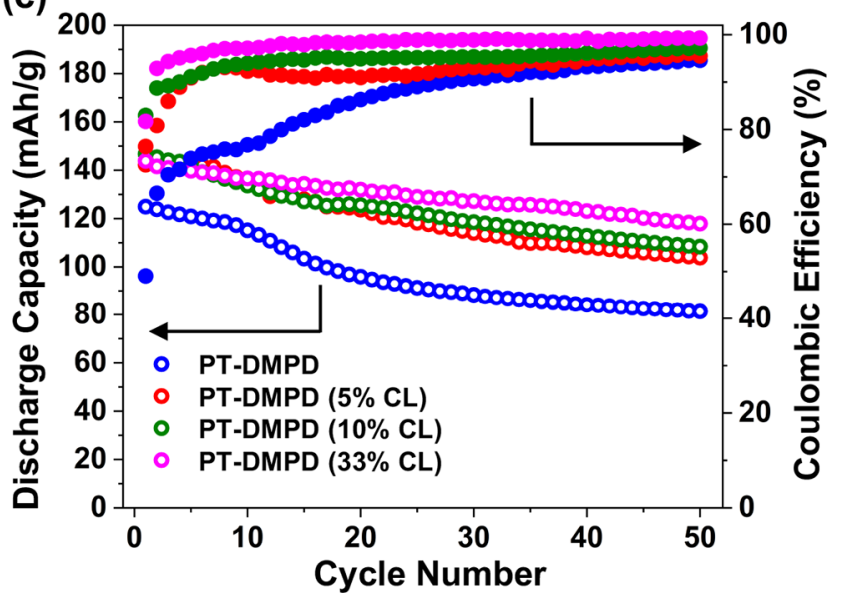

Figure 4. (a) Cross-linker (CL) structure and material design. (b) Initial charge-discharge profiles of PT-DMPD, PT-DMPD (5\% CL), PT-DMPD (10\% CL), and PT-DMPD (33\% CL) at 5 C. (c) Cycling performance of coin cells with $0.55 \mathrm{mg} / \mathrm{cm}^{2}$ loading of PT-DMPD, PT-DMPD (5\% CL), PT-DMPD (10\% CL), and PT-DMPD (33\% $\mathrm{CL})$ at $5 \mathrm{C}$.

increasing discharge rates, the rate capabilities of PT-DMPD (10\% CL) and PT-DMPD (33\% CL), the two materials displaying the highest discharge capacities, were investigated 
between 2.8 and $4.3 \mathrm{~V}$. Figure 5 compares the discharge capacities of these materials charged at $1 \mathrm{C}$ and discharged at

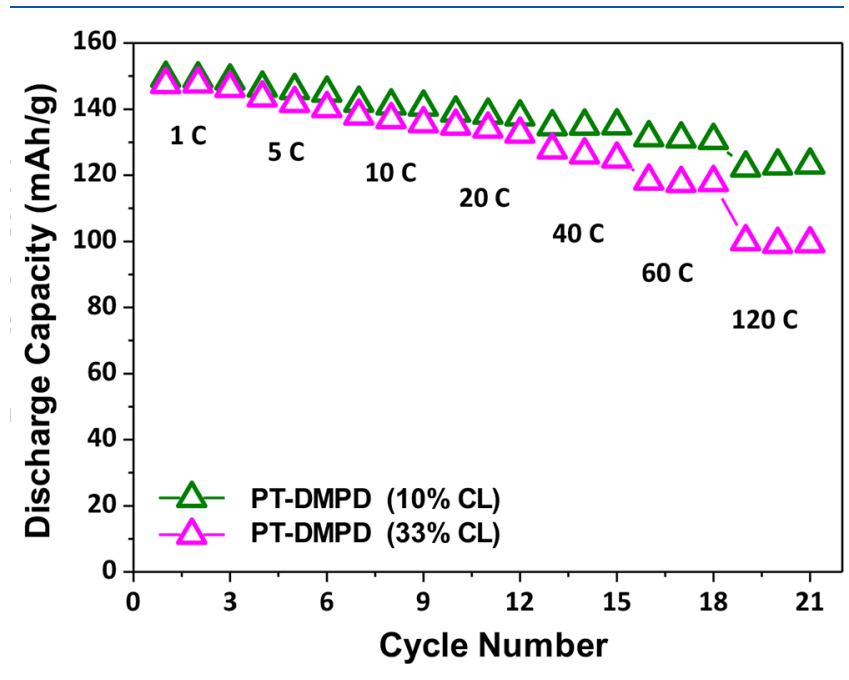

Figure 5. Discharge capacities of PT-DMPD (10\% CL) and PTDMPD $(33 \% \mathrm{CL})$ at C-rates from 1 to $120 \mathrm{C}$.

C-rates of $1,5,10,20,40,60$, and 120 C. Significantly, excellent capacity retention (82\%) was observed in PT-DMPD (10\% CL) between even the most extreme discharging rates, 1 to $120 \mathrm{C}$. While similar capacities are observed at the lower rates for both materials, an apparent decrease in capacity is evident in PT-DMPD (33\% CL) at higher discharge rates. We attribute this to a decrease in the rate of counterion transport through the more densely cross-linked material. Notably, the PT-DMPD (10\% CL) material retained a very high discharge capacity of $122 \mathrm{mAh} / \mathrm{g}$ at the ultrahigh C-rate of $120 \mathrm{C}^{29}$

Encouraged by the fast discharge rates exhibited by these materials, electrochemical impedance spectroscopy (EIS) was used to measure the charge transfer resistance of PT-DMPD $(10 \% \mathrm{CL})$ in a coin cell to explore the origin of the ultrahigh rate behavior. ${ }^{30-32}$ In impedance measurements, a high frequency semicircle is attributed to the double layer and the kinetics of the active material (Figure 6). In addition, the low frequency behavior is attributed to transport effects. The high frequency semicircle was fit to a simplified Randles model, and the charge transfer resistances obtained are given as an inset.

As expected, the charge transfer resistance was a function of the oxidation state of the polymer. The charge transfer resistances near the redox couple around $3.6 \mathrm{~V}$ are much lower than the charge transfer resistances near 4.1 and $3.1 \mathrm{~V}$. Overall, the charge transfer resistance was between 80 and $230 \Omega$. When compared to literature reports, these values are similar to or lower than comparable systems, reflecting fast charge transfer kinetics. ${ }^{7,9,30-33}$ This facile kinetic behavior allows the battery to operate at high C-rates without excessive overpotentials. The low overpotentials, in turn, are one of the reasons for the high rate cycling capability without significant loss of capacity. The low charge transfer resistance of this material is exemplified by retention of capacity and stable cycling in coin cells with $75 \%$ active material loading (Figure S4).

In conclusion, we have designed, synthesized, and tested a class of high energy phenothiazine-derived redox-active polymers that deliver high capacities at ultrafast discharge rates and high operating voltages in lithium ion batteries. The

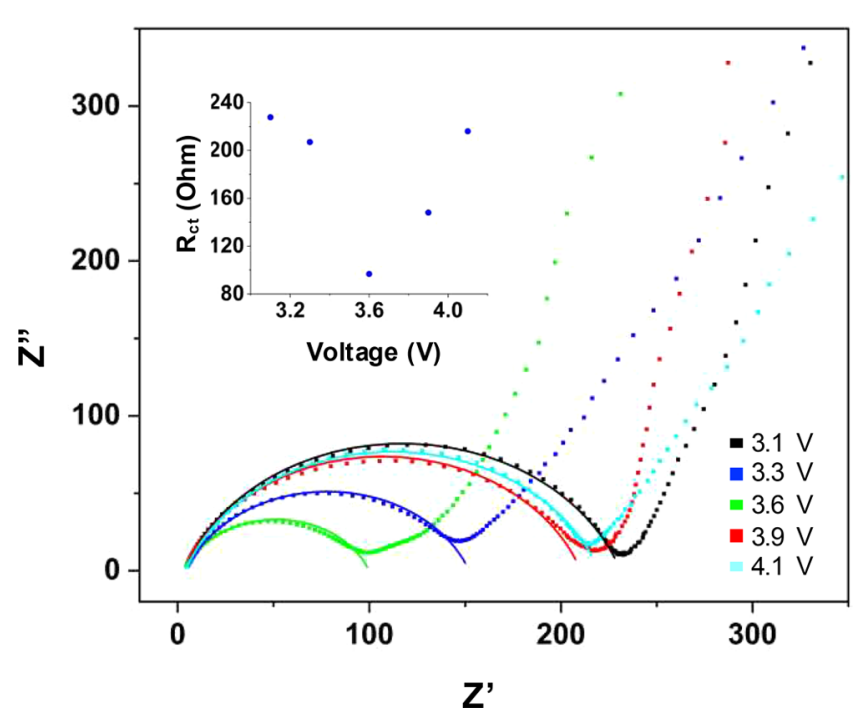

Figure 6. Electrochemical impedance spectra of PT-DMPD (10\% CL) at various charge states reflect fast charge transfer kinetics dependent on the oxidation state of the polymer. Inset shows the charge transfer resistance $\left(R_{\mathrm{ct}}\right)$ as a function of the potential of the device.

initial capacity fade, due to electrode dissolution, was largely mitigated through the implementation of cross-linked materials, which led to dramatically improved cycling performance, discharge capacity, and Coulombic efficiency without compromising the material's rate capability. PT-DMPD (10\% CL) retained $82 \%$ capacity at an unparalleled $120 \mathrm{C}$ rate. These results validate our design principles and are highly instructive for future discoveries of organic electrodes with competitive energy densities and superior power densities for electrical energy storage applications.

\section{ASSOCIATED CONTENT}

S Supporting Information

The Supporting Information is available free of charge on the ACS Publications website at DOI: 10.1021/acsaem.8b00778.

General experimental considerations, experimental procedures, coin cell construction, electrochemical measurement procedures, and additional supporting data (PDF)

\section{AUTHOR INFORMATION}

\section{Corresponding Author}

*E-mail: bpf46@cornell.edu.

ORCID $\odot$

Burak Ulgut: 0000-0002-4402-0033

Geoffrey W. Coates: 0000-0002-3400-2552

Héctor D. Abruña: 0000-0002-3948-356X

Brett P. Fors: 0000-0002-2222-3825

\section{Author Contributions}

${ }^{\dagger}$ B.M.P., D.R., and L.S. contributed equally.

\section{Notes}

The authors declare no competing financial interest.

\section{ACKNOWLEDGMENTS}

This work was primarily supported by the Cornell Center for Materials Research with funding from the NSF MRSEC program (DMR-1719875). 


\section{REFERENCES}

(1) Novák, P.; Müller, K.; Santhanam, K. S. V.; Haas, O. Electrochemically Active Polymers for Rechargeable Batteries. Chem. Rev. 1997, 97, 207-282.

(2) Liang, Y.; Tao, Z.; Chen, J. Organic Electrode Materials for Rechargeable Lithium Batteries. Adv. Energy Mater. 2012, 2, 742-769.

(3) Schon, T. B.; McAllister, B. T.; Li, P.-F.; Seferos, D. S. The Rise of Organic Electrode Materials for Energy Storage. Chem. Soc. Rev. 2016, 45, 6345-6404.

(4) Snook, G. A.; Kao, P.; Best, A. S. Conducting-Polymer-Based Supercapacitor Devices and Electrodes. J. Power Sources 2011, 196, $1-12$.

(5) Hudak, N. S. Chloroaluminate-Doped Conducting Polymers as Positive Electrodes in Rechargeable Aluminum Batteries. J. Phys. Chem. C 2014, 118, 5203-5215.

(6) Zhang, H.; Deng, Q.; Zhou, A.; Liu, X.; Li, J. Porous $\mathrm{Li}_{2} \mathrm{C}_{8} \mathrm{H}_{4} \mathrm{O}_{4}$ Caoted with N-Doped Carbn By Using CVD as an Anode Material for Li-Ion Batteries. J. Mater. Chem. A 2014, 2, 5696-5702.

(7) Song, Z.; Qian, Y.; Gordin, M. L.; Tang, D.; Xu, T.; Otani, M.; Zhan, H.; Zhou, H.; Wang, D. Polyanthraquinone as a Reliable Organic Electrode for Stable and Fast Lithium Storage. Angew. Chem., Int. Ed. 2015, 54, 13947-13951.

(8) Liang, Y.; Chen, Z.; Jing, Y.; Rong, Y.; Facchetti, A.; Yao, Y. Heavily n-Dopable $\pi$-Conjugated Redox Polymers with Ultrafast Energy Storage Capability. J. Am. Chem. Soc. 2015, 137, 4956-4959.

(9) Wang, S.; Wang, Q.; Shao, P.; Han, Y.; Gao, X.; Ma, L.; Yuan, S.; Ma, X.; Zhou, J.; Feng, X.; Wang, B. Exfoliation of Covalent Organic Frameworks into Few-Layer Redox-Active Nanosheets as Cathode Materials for Lithium-Ion Batteries. J. Am. Chem. Soc. 2017, 139, $4258-4261$.

(10) Lin, H.-C.; Li, C.-C.; Lee, J.-T. Nitroxide Polymer Brushes Grafted onto Silica Nanoparticles as Cathodes for Organic Radical Batteries. J. Power Sources 2011, 196, 8098-8103.

(11) Wang, Y.-H.; Hung, M.-K.; Lin, C.-H.; Lin, H.-C.; Lee, J.-T. Patterned Nitroxide Polymer Brushes for Thin-Film Cathodes in Organic Radical Batteries. Chem. Commun. 2011, 47, 1249-1251.

(12) Sarukawa, T.; Oyama, N. Electrochemical Activity of SulfurLinked Tetrathionaphthalene Polymer. J. Electrochem. Soc. 2010, 157, F23-F29.

(13) Kiya, Y.; Iwata, A.; Sarukawa, T.; Henderson, J. C.; Abruña, H. D. Poly[Dithio-2,5-(1,3,4-Thiadiazole)] (PDMcT)-Poly(3,4-Ethylenedioxythiophene) (PEDOT) Composite Cathode for High-Energy Lithium/Lithium-Ion Rechargeable Batteries. J. Power Sources 2007, $173,522-530$.

(14) Davoglio, R. A.; Biaggio, S. R.; Rocha-Filho, R. C.; Bocchi, N. Bilayered Nanofilm of Polypyrrole and Poly(DMcT) for HighPerformance Battery Cathodes. J. Power Sources 2010, 195, 29242927.

(15) Häupler, B.; Burges, R.; Friebe, C.; Janoschka, T.; Schmidt, D.; Wild, A.; Schubert, U. S. Poly(exTTF): A Novel Redox-Active Polymer as Active Material for Li-Organic Batteries. Macromol. Rapid Commun. 2014, 35, 1367-1371.

(16) Imada, Y.; Nakano, H.; Furukawa, K.; Kishi, R.; Nakano, M.; Maruyama, H.; Nakamoto, M.; Sekiguchi, A.; Ogawa, M.; Ohta, T.; Yamamoto, Y. Isolation of Hypervalent Group-16 Radicals and Their Application in Organic-Radical Batteries. J. Am. Chem. Soc. 2016, 138, 479-482.

(17) Speer, M. E.; Kolek, M.; Jassoy, J. J.; Heine, J.; Winter, M.; Bieker, P. M.; Esser, B. Thianthrene-Functionalized Polynorbornenes as High-Voltage Materials for Organic Cathode-Based Dual-Ion Batteries. Chem. Commun. 2015, 51, 15261-15264.

(18) Peng, C.; Ning, G.-H.; Su, J.; Zhong, G.; Tang, W.; Tian, B.; Su, C.; Yu, D.; Zu, L.; Yang, J.; Ng, M.-F.; Hu, Y.-S.; Yang, Y.; Armand, M.; Loh, K. P. Reversible Multi-Electron Redox Chemistry of $\pi$ Conjugated N-Containing Heteroaromatic Molecule-Based Organic Cathodes. Nat. Energy 2017, 2, 17074.

(19) Golriz, A.; Suga, T.; Nishide, H.; Berger, R.; Gutmann, J. S. Phenothiazine-Functionalized Redox Polymers for a New CathodeActive Material. RSC Adv. 2015, 5, 22947-22950.
(20) Kolek, M.; Otteny, F.; Schmidt, P.; Mück-Lichtenfeld, C.; Einholz, C.; Becking, J.; Schleicher, E.; Winter, M.; Bieker, P.; Esser, B. Ultra-High Cycling Stability of Poly(Vinylphenothiazine) as a Battery Cathode Material Resulting From $\pi-\pi$ Interactions. Energy Environ. Sci. 2017, 10, 2334-2341.

(21) Godet-Bar, T.; Lepretre, J.-C.; Le Bacq, O.; Sanchez, J.-Y.; Deronzier, A.; Pasturel, A. Electrochemical and $\mathrm{Ab}$ Initio Investigations to Design a New Phenothiazine Based Organic Redox Polymeric Material for Metal-Ion Battery Cathodes. Phys. Chem. Chem. Phys. 2015, 17, 25283-25296.

(22) (a) Truong, T.-T.; Coates, G. W.; Abruña, H. D. High Power Organic Cathodes Using Thin Films of Electropolymerized Benzidine Polymers. Chem. Commun. 2015, 51, 14674-14677.

(23) Maiti, D.; Fors, B. P.; Henderson, J. L.; Nakamura, Y.; Buchwald, S. L. Palladium-Catalyzed Coupling of Functionalized Primary and Secondary Amines with Aryl and Heteroaryl Halides: Two Ligands Suffice in Most Cases. Chem. Sci. 2011, 2, 57-68.

(24) Kinzel, T.; Zhang, Y.; Buchwald, S. L. A New Palladium Precatalyst Allows for the Fast Suzuki-Miyaura Coupling Reactions of Unstable Polyfluorophenyl and 2-Heteroaryl Boronic Acids. J. Am. Chem. Soc. 2010, 132, 14073-14075.

(25) We hypothesize the two small redox couples at 3.6 and $4.0 \mathrm{~V}$ vs $\mathrm{Li} / \mathrm{Li}^{+}$correspond to redox active end groups of the polymers.

(26) Peled, E.; Sternberg, Y.; Gorenshtein, A.; Lavi, Y. LithiumSulfur Battery: Evaluation of Dioxolane-Based Electrolytes. J. Electrochem. Soc. 1989, 136, 1621-1625.

(27) Mikhaylik, Y. V.; Akridge, J. R. Polysulfide Shuttle Study in the Li/S Battery System. J. Electrochem. Soc. 2004, 151, A1969-A1976.

(28) Diao, Y.; Xie, K.; Xiong, S.; Hong, X. Shuttle Phenomenon the Irreversible Oxidation Mechanism of Sulfur Active Material in $\mathrm{Li}-$ S Battery. J. Power Sources 2013, 235, 181-186.

(29) By comparison, the reported materials retain $82 \%$ of initial capacity $(150 \mathrm{mAh} / \mathrm{g})$ at $120 \mathrm{C}$, whereas the phenothiazine-based material reported in 20 retains $52 \%$ of initial capacity $(79 \mathrm{mAh} / \mathrm{g})$ at $100 \mathrm{C}$.

(30) Bhosale, M. E.; Krishnamoorthy, K. Chemically Reduced Organic Small-Molecule-Based Lithium Battery with Improved Efficiency. Chem. Mater. 2015, 27, 2121-2126.

(31) Zhang, K.; Guo, C.; Zhao, Q.; Niu, Z.; Chen, J. HighPerformance Organic Lithium Batteries with an Ether-Based Electrolyte and 9,10-Anthraquinone (AQ)/CMK-3 Cathode. Adv. Sci. 2015, 2,1500018

(32) Wu, H.; Shevlin, S. A.; Meng, Q.; Guo, W.; Meng, Y.; Lu, K.; Wei, Z.; Guo, Z. Flexible and Binder-Free Organic Cathode for HighPerformance Lithium-Ion Batteries. Adv. Mater. 2014, 26, 33383343.

(33) Song, Z.; Qian, Y.; Liu, X.; Zhang, T.; Zhu, Y.; Yu, H.; Otani, M.; Zhou, H. A Quinone-Based Oligomeric Lithium Salt for Superior Li-Organic Batteries. Energy Environ. Sci. 2014, 7, 4077-4086. 